University of Wollongong

Research Online

2008

\title{
Assessment of need and capacity to benefit for people with a disability requiring aids, appliances and equipment
}

Malcolm R. Masso

University of Wollongong, mmasso@uow.edu.au

Alan G. Owen

University of Wollongong, aowen@uow.edu.au

Tara L. Stevermuer

University of Wollongong, hurst@uow.edu.au

Kathryn E. Williams

University of Wollongong, kathrynw@uow.edu.au

Kathy Eagar

University of Wollongong, keagar@uow.edu.au

Follow this and additional works at: https://ro.uow.edu.au/ahsri

Research Online is the open access institutional repository for the University of Wollongong. For further information contact the UOW Library: research-pubs@uow.edu.au 


\title{
Assessment of need and capacity to benefit for people with a disability requiring aids, appliances and equipment
}

\begin{abstract}
Aim: To develop an equitable system for allocating equipment, aids and appliances to adults with disabilities based on assessment of need and capacity to benefit for use by occupational therapists, who are the main professional group involved in assessing and prioritising applications. Methods: An assessment tool was developed, pilot tested and field tested at four sites in New South Wales.

Assessments were undertaken in parallel with existing systems. Feedback on use of the tool was obtained from those conducting the assessments and those making decisions to fund applications for equipment based on the assessments. Results: One hundred and six assessments were undertaken. Applications for bed, sleeping and seating equipment and equipment to assist with mobility, toileting, showering and transfers accounted for $94.2 \%$ of equipment requested. Provision of equipment was expected to have greatest impact on the physical effort and safety of carers and the safety and quality of life of applicants. Regression analysis identified assessment items that explain variation between applicants and that can avoid unnecessary data collection. Conclusions: The assessment tool provides a standardised method for assessing requests for equipment based on the twin concepts of need and capacity to benefit. The results support the use of both concepts as the foundation of the assessment process. Further development is required, particularly to move to the next stage of using the assessment tool as the basis for prioritising applications for equipment
\end{abstract}

\section{Keywords}

assessment, benefit, people, disability, need, equipment, aids, capacity, appliances, requiring

\section{Publication Details}

Masso, M. R., Owen, A. G., Stevermuer, T. L., Williams, K. E. \& Eagar, K. M. (2008). Assessment of need and capacity to benefit for people with a disability requiring aids, appliances and equipment. Australian Occupational Therapy Journal, 56 (5), 315-323. 


\title{
Assessment of need and capacity to benefit for people with a disability requiring aids, appliances and equipment
}

\author{
Malcolm Masso, Alan Owen, Tara Stevermuer, Kathryn Williams and \\ Kathy Eagar \\ Centre for Health Service Development, University of Wollongong, New South Wales, Australia
}

\begin{abstract}
Aim: To develop an equitable system for allocating equipment, aids and appliances to adults with disabilities based on assessment of need and capacity to benefit for use by occupational therapists, who are the main professional group involved in assessing and prioritising applications.

Methods: An assessment tool was developed, pilot tested and field tested at four sites in New South Wales. Assessments were undertaken in parallel with existing systems. Feedback on use of the tool was obtained from those conducting the assessments and those making decisions to fund applications for equipment based on the assessments.

Results: One hundred and six assessments were undertaken. Applications for bed, sleeping and seating equipment and equipment to assist with mobility, toileting, showering and transfers accounted for $94.2 \%$ of equipment requested. Provision of equipment was expected to have greatest impact on the physical effort and safety of carers and the safety and quality of life of applicants. Regression analysis identified assessment items that explain variation between applicants and that can avoid unnecessary data collection.

Conclusions: The assessment tool provides a standardised method for assessing requests for equipment based on the twin concepts of need and capacity to benefit. The results support the use of both concepts as the foundation of the assessment process. Further development is required, particularly to move to the next stage of using the assessment tool as the basis for prioritising applications for equipment.
\end{abstract}

Malcolm Masso BSc(Econ), MNA, MPH; Senior Research Fellow. Alan Owen BSc(Hons); Senior Research Fellow. Tara Stevermuer BA, MAPPStat; Research Fellow. Kathryn Williams BA(Hons), BA(Journ); Research Fellow. Kathy Eagar PhD; Professor, Director.

Correspondence: Malcolm Masso, Centre for Health Service Development, University of Wollongong, NSW 2522, Australia. Email: mmasso@uow.edu.au

Accepted for publication 16 May 2008.

(C) 2008 The Authors

Journal compilation (c) 2008 Australian Association of Occupational Therapists
KEY WORDS capacity to benefit, disability, function, health priorities, needs assessment.

\section{Introduction}

Providing health and community care services to promote independence rather than dependence requires decisions at many levels regarding how to allocate resources. Some of the parameters for such decisions are indicated by a systematic review of occupational therapy interventions for elderly people living at home (Steultjens et al., 2004). The review found that assistive devices, training, comprehensive occupational therapy, home hazard assessment, counselling of the primary caregiver and information on fall prevention and social participation were useful in promoting an independence model.

The main principles identified in the literature regarding how allocation should occur fall into three categories: need, maximising and egalitarian principles, that is, resources should be distributed according to 'need' to obtain maximum benefit and to reduce inequality (Cookson \& Dolan, 2000). Need and equality come together around the idea that persons in equal need should be treated the same and those in greater need should be treated more favourably than those with less need (Hauck, Smith \& Goddard, 2002). For health services 'need' is characterised as degree of ill health. For disability services the equivalent is degree of disability, typically assessed as degree of functional limitations. At its most extreme this has been called the 'rule of rescue', recognising that extremes of ill-health, or disability, require a response by society, irrespective of any potential benefits (Hadorn, 1991).

Often, the processes underpinning decisions about how to allocate resources are not explicitly stated or, if they are, are based on a mix of 'custom and practice' and local policies. Prioritisation essentially involves a two-step process, however simple or sophisticated, or implicit or explicit, that process might be. It involves translating concepts such as 'need' and 'benefit' into something that can be measured and then taking the results from that measurement (assessment) and assigning priority. 
Decision-making can include whether a particular client will receive any services, or services of a given type or from a specific set of providers or funding sources (Weissert, Chernew \& Hirth, 2003).

The study described here sought to use the above principles in responding to a particular problem. Eligible residents of New South Wales (NSW) with a long-term disability can apply to the Program of Appliances for Disabled People (PADP) for financial assistance to purchase aids, appliances and equipment (henceforth referred to simply as equipment), mainly to assist with mobility, seating, toileting, showering and transfer. Funding for PADP is allocated to eight area health services in NSW, each with a PADP lodgement centre and allocation committee with responsibility for decisions about the priority of applications based on need.

The aim of the study was to determine whether it is possible to standardise the assessment of the needs of applicants and to standardise the way that priorities for the allocation of equipment are set. It included three stages: review and consultation, development and pilot testing, and field testing. The study developed tools for assessing both adults and children, with a separate assessment for incontinence. The development of the adult assessment tool is reported here.

The first stage involved a literature and website search using search engines for occupational therapy and physiotherapy (OTseeker and PEDro), with keywords of aids and appliances, medical aids and functional needs. The results indicated that the focus of assessment was the functional status of applicants and the extent to which the provision of equipment would assist applicants in undertaking everyday self-care and domestic tasks. This review built on previous work using function as a proxy for 'need' (Owen, Poulos \& Eagar, 2001; Stevermuer, Owen \& Eagar, 2003), including a review of existing measures to assess both self-care activities of daily living and domestic (instrumental) activities of daily living (Eagar, Owen, Marosszeky \& Poulos, 2006). As in other related work (Eagar et al.; Green, Eagar \& Owen, 2006) it was assumed that information about functional status was necessary, but not sufficient, for helping committees make decisions. It was also assumed that one assessment system may not be suitable for all equipment across all disabilities.

Following the review, a consultation paper was distributed to stakeholders that included discussion about the concepts of 'need' and 'capacity to benefit' (Eagar, Sansoni, Harvey \& Owen, 2003). Drawing on the work of Bradshaw (1972) the paper identified key domains that might be included in the assessment process. Responses to the consultation paper indicated strong support for the assessment process proposed in the paper, with $89 \%$ of respondents supporting the collection of information on capacity to benefit, although some respondents highlighted the potential difficulties with how it might be assessed.

The project was approved by the University of Wollongong and Illawarra Area Health Service Human
Research Ethics Committee. PADP lodgement centres were approached to participate in the study and consented to involvement on behalf of their staff. The centres were free to withdraw participation at any time.

\section{Methods}

Assessments of applicants are carried out by therapists who write narrative reports and make recommendations to an allocation committee. The committee then makes decisions based on a number of related factors including applicant eligibility, the level of need as indicated in the report and the available budget. The new instrument was intended to standardise the process by using common measurement scales for inclusion in assessment reports by therapists and by giving committees a set of recommendations that included priority rating scores. The common elements were not intended to fully replace narrative reports.

\section{Instrument development}

The results of the literature search, PADP application forms already in use and feedback on the consultation paper formed the basis for developing an adult assessment tool with five components (for details see Table 1):

1 Self-care by use of the Barthel index (Collin, Wade, Davies \& Horne, 1988) with modified scoring. The scoring was extended from three to five levels to improve its discriminatory ability and to make it more sensitive to change. The items themselves were not changed.

2 Domestic functioning using the Australian-modified Lawton and Brody domestic functioning instrument (Green et al., 2006; Lawton \& Brody, 1969).

3 Items on the care and assistance provided to the applicant.

4 Items on the impact of the equipment on carers.

5 Items on the expected benefits of the equipment for clients.

The self-care and domestic functioning assessments were designed to assess the individual applicant without the equipment they were requesting and then again, with that equipment. Current care and assistance needs were assessed by estimating the average number of hours of care provided to the client each week by his/ her primary carer, other informal carers and paid or formal services and how this would change if the requested equipment were provided. Together, these three sections of the assessment provided an overall measure of need (i.e. assessment without the equipment) and a measure of the increase in function expected to result from providing the equipment.

All other items in the assessment tool required a judgement about the impact of the equipment. On a scale of 1 (no change) to 4 (significant improvement), assessors indicated the predicted impact of the equipment on 
TABLE 1: Domains and items in the adult assessment tool

\begin{tabular}{|c|c|c|}
\hline Domain & Items & Rating scale \\
\hline \multirow[t]{10}{*}{$\begin{array}{l}\text { Self-care functional } \\
\text { assessment }\end{array}$} & Bowels & $\begin{array}{l}\text { Change in total score for the } 10 \text { items, } \\
\text { without and with the equipment: }\end{array}$ \\
\hline & Bladder & $1=$ no change \\
\hline & Grooming & $2=$ slight change $(1$ or 2 points improvement $)$ \\
\hline & Toilet use & $3=$ moderate change ( 3 or 4 points improvement $)$ \\
\hline & Feeding & $4=$ significant change ( 5 points or more improvement $)$ \\
\hline & Transfer & \\
\hline & Indoor mobility & \\
\hline & Dressing & \\
\hline & Stairs & \\
\hline & Bathing & \\
\hline \multirow[t]{8}{*}{$\begin{array}{l}\text { Domestic functioning } \\
\text { assessment }\end{array}$} & Use of telephone & $\begin{array}{l}\text { Change in total score for the eight items, } \\
\text { without and with the equipment: }\end{array}$ \\
\hline & Shopping & $1=$ no change \\
\hline & Food preparation & $2=$ slight change ( 1 or 2 points improvement $)$ \\
\hline & Housekeeping & $3=$ moderate change ( 3 or 4 points improvement $)$ \\
\hline & Laundry & $4=$ significant change ( 5 points or more improvement) \\
\hline & Outdoor mobility & \\
\hline & Responsibility for medications & \\
\hline & Ability to manage finances. & \\
\hline \multirow{7}{*}{$\begin{array}{l}\text { Care and assistance } \\
\text { provided to applicant }\end{array}$} & Hours of care and assistance & $1=$ no change in hours of care or increase in hours of care \\
\hline & provided to the applicant & $2=$ slight decrease $(2 \mathrm{~h}$ per week or less $)$ \\
\hline & by primary carer, by a formal service, & $3=$ moderate decrease ( $3-7 \mathrm{~h}$ per week) \\
\hline & or other informal arrangements. & $4=$ significant decrease $(8 \mathrm{~h}$ or more per week) \\
\hline & Sustainability of current & $1=$ arrangements sustainable \\
\hline & care arrangements & $\begin{array}{l}2=\text { arrangements likely to break down in long } \\
\text { term ( } 6 \text { months or more) }\end{array}$ \\
\hline & & $\begin{array}{l}4=\text { arrangements likely to break down in short } \\
\text { term (less than } 6 \text { months) }\end{array}$ \\
\hline \multirow[t]{5}{*}{ Impact on carers } & Physical effort & Each item rated on the following scale \\
\hline & Emotional well-being & $1=$ no change \\
\hline & Independence & 2 = slight improvement \\
\hline & Quality of life & $3=$ moderate improvement \\
\hline & Safetyt & $4=$ significant improvement \\
\hline \multirow[t]{5}{*}{ Impact on client } & $\begin{array}{l}\text { Likelihood that the applicant will } \\
\text { remain in the community }\end{array}$ & Each item rated on the following scale \\
\hline & Quality of life & $1=$ no change \\
\hline & $\begin{array}{l}\text { Participation in social and/or } \\
\text { community activities. }\end{array}$ & $2=$ slight change \\
\hline & Safetyt & $3=$ moderate change \\
\hline & Health statust & $4=$ significant change \\
\hline
\end{tabular}

Notes: (1) Individual items on the modified Barthel index rated on a scale ranging from $1=$ maximum dependency to $5=$ independence. Maximum total score $=50$.

(2) Individual items on the Australian modified Lawton and Brody domestic functioning assessment rated on a scale ranging from 1 = dependent to independent ( 3 or 4 ). Maximum total score $=30$.

(3) For further information about the modified domestic functioning assessment see Eagar and Woods (1999); Eagar et al. (2006), Green et al. (2006).

(4) tDenotes items added after pilot testing. 
carers' physical effort, safety, emotional well-being, independence and quality of life. These domains were based on the literature and were consistent with feedback from practitioners during the consultation process. In addition, assessors were asked to make a judgement about the sustainability of care arrangements (including self-care, if applicable) without the requested item.

The expected impacts on the client were assessed in five domains: risk of institutionalisation; quality of life; participation in social/community activities; safety and health status. Again, the selection of these domains was based on a review of the literature (Owen et al., 2001), stakeholder consultation and an examination of currently used PADP documents. The goal was not to conduct a detailed investigation of these aspects of the client's life, but to determine the likely impact of the equipment on this client relative to others, to assist in priority rating. The usefulness of these domains for this purpose was assessed as part of the field trial described below.

\section{Pilot testing and field testing}

The assessment tool was initially pilot tested at one PADP site resulting in 34, mostly minor, changes to the tool based on recommendations from occupational therapists and others using the tool to carry out assessments. The basic format remained unchanged but additional items for impact on safety of carers and impact on safety and health status of applicants were included. The final tool was considerably longer and more comprehensive than those in current practice.

The assessment tool was then field tested at four PADP sites. Standardisation for the study was limited to the use of the assessment tool and did not include any changes to organisational arrangements for processing applications. The field trial sought to answer a number of questions:

- What is the best mix of assessments of consumer need and expected benefits that might result in a reliable priority rating?

- Is the tool acceptable to those undertaking the assessments, including the burden of data collection?

- How well does the assessment tool fit with current professional practice?

- Is the assessment tool sensitive enough to identify functional status with and without the requested equipment?

- How does the proposed assessment tool compare with existing tools?

Training sessions were conducted at each site, supported by a training manual supplied to assessors. Most attendees were occupational therapists, reflecting the group of health professionals primarily involved in current systems. Informal feedback at the training sessions was very positive with support for introducing a common, standardised, assessment system, although not necessarily the one developed for the study. PADP committees received a demonstration of the way the tool would be used, but were not trained in its use. Each site collected data for 2 months and chose to test the tool 'in parallel' to its existing system, using a database developed for the study.

A feedback form was used to allow assessors to provide comments regarding each assessment. Members of the project team also attended PADP committee meetings to observe deliberations and receive feedback about use of the tool.

\section{Analysis}

The results were analysed separately for each of the three groups of participants: applicants, those assessing applicants (primarily occupational therapists) and those involved in processing the results of the assessments and making decisions about which applications to fund.

Statistical methods for analysing the results for clients included descriptive statistics and regression analysis. Regression analysis was used to determine which, if any, items could be dropped from the assessment. In determining this, there is a trade-off between the need to explain variation between clients to a satisfactory degree (by including more items) and the need to develop an assessment tool that is easy to administer (by including fewer items). The aim is to get the best result, in terms of variation explained, in the most parsimonious way. For the purposes of the analysis it was assumed that inclusion of sufficient items to explain at least $90 \%$ of the variation would represent the best option, with second and third best options including more items, and hence explaining more variation.

Analysis of the qualitative results for assessors and decision-makers was undertaken by one member of the research team who identified themes and findings from the feedback forms and from an analysis of the discourse at meetings.

\section{Results}

\section{Applicants and equipment requested}

A total of 106 adult assessments were undertaken. Not all items were completed for some assessments. Disabilities of neuromusculoskeletal and mental function accounted for almost three-quarters of all applicants. Most applicants reported two or three disabilities (Table 2). In general, two to three items of equipment were requested by each applicant. Applications for beds and sleeping equipment, seating equipment and equipment to assist with mobility, toileting, showering and transfers accounted for $94.2 \%$ of all items requested (Table 3). Client characteristics and the items requested were broadly similar (as far as such data are available) to what would be expected from the population of PADP applicants. 
TABLE 2: Disabilities of adult applicants

Function or body system involved - determined using the International Classification of Functioning, Disability and Health (ICF)

$\begin{array}{cccc}\begin{array}{l}\text { Number }(\%) \text { of } \\ \text { applications }\end{array} & \begin{array}{c}\text { Average age } \\ \text { of applicant }\end{array} & \begin{array}{l}\text { Average number } \\ \text { of disabilities }\end{array} & \begin{array}{l}\text { Proportion of } \\ \text { male applicants }\end{array} \\ 49(46.2 \%) & 73.8 & 3.0 & 43.8 \% \\ & & & \\ 29(27.4 \%) & 55.9 & 2.0 & 62.1 \% \\ 19(17.9 \%) & 71.5 & 3.9 & 52.6 \% \\ & & & \\ 3(2.8 \%) & 75.0 & 4.0 & 66.7 \% \\ 1(0.9 \%) & 60.0 & 5.0 & 0.0 \% \\ 1(0.9 \%) & \text { n.a. } & 2.0 & 100.0 \% \\ 4(3.8 \%) & 70.0 & 1.8 & 0.0 \% \\ 106(100 \%) & 69.3 & 2.9 & 50.5 \%\end{array}$

TABLE 3: Items requested by adults from Program of Appliances for Disabled People

\begin{tabular}{lcc}
\hline Category of equipment & $\begin{array}{c}\text { No. of } \\
\text { items }\end{array}$ & $\begin{array}{c}\text { Percentage } \\
\text { of total }\end{array}$ \\
\hline Toileting and showering aids & 75 & $31.3 \%$ \\
Mobility aids & 73 & $30.4 \%$ \\
Beds and sleeping equipment & 45 & $18.8 \%$ \\
Seating equipment & 20 & $8.3 \%$ \\
Transfer aids & 13 & $5.4 \%$ \\
Pressure garments and pressure & 8 & $3.3 \%$ \\
relief equipment & 4 & \\
Orthoses and footwear & 1 & $0.4 \%$ \\
Aids to nutrition & 1 & $0.4 \%$ \\
Technological aids to inclusion & 240 & $100 \%$ \\
Total & & \\
\hline
\end{tabular}

\section{Impact on function}

Every item on the self-care functional assessment recorded at least one change predicted if the equipment was provided. The percentage of applicants whose functioning would change ranged from $1.9 \%$ (for the stairs item) to $41.5 \%$ (bathing). Results are summarised in Table 4. The amount of change overall was small. This was expected, as applicants were seeking specific items of equipment to improve specific aspects of their functioning, not aiming for a functional improvement in all aspects of their lives. When considering only those assessments in which changes were predicted, the amount of change in functioning was typically more than one point (one point was the smallest change possible).

A similar pattern can be seen in the domestic functioning assessment (Table 4). Again, changes were recorded for every item, ranging from $1.0 \%$ (telephone) to $27.5 \%$ (shopping). For those assessments where provision of equipment was expected to improve functioning, the amount of change was again typically more than one point.

The regression analysis identified that the number of assessment items could be reduced, with only a small reduction in its ability to explain variation. In order (with variation shown in parentheses), the self-care assessment can be reduced to:

- Bladder, toilet use, indoor mobility (90.5\%)

- Bladder, toilet use, transfer, indoor mobility (93.1\%)

- Bladder, toilet use, transfer, indoor mobility, bathing (95.0\%).

Likewise, the assessment of domestic functioning can be reduced to:

- Shopping, housekeeping, outdoor mobility (94.1\%)

- Shopping, housekeeping, laundry, outdoor mobility (96.4\%)

- Shopping, food preparation, housekeeping, laundry, outdoor mobility $(98.0 \%)$

\section{Impact on care and assistance provided}

In one-third of applications it was expected that provision of the requested equipment would reduce the hours of care provided to the applicant by the primary carer (mean reduction of $5.5 \mathrm{~h}$ per week). Although more change was expected in the hours of care provided informally (mean reduction of $8 \mathrm{~h}$ per week) and by paid carers (mean reduction of $25.5 \mathrm{~h}$ per week), these were 
TABLE 4: Functional assessment - without requested equipment and expected change with requested equipment

\begin{tabular}{|c|c|c|c|c|c|}
\hline \multirow[b]{2}{*}{ Item name } & \multirow{2}{*}{$\begin{array}{l}\text { Number of } \\
\text { assessments }\end{array}$} & \multirow{2}{*}{$\begin{array}{l}\text { Mean score } \\
\text { without } \\
\text { equipment }\end{array}$} & \multicolumn{2}{|c|}{$\begin{array}{l}\text { Applicants with changed } \\
\text { functioning with } \\
\text { requested equipment }\end{array}$} & \multirow{2}{*}{$\begin{array}{l}\text { Mean change in score } \\
\text { for applicants with } \\
\text { changed functioning }\end{array}$} \\
\hline & & & $n$ & $\%$ & \\
\hline \multicolumn{6}{|c|}{ Self care functional assessment (maximum score $=5$ ) } \\
\hline Bowels & 103 & 3.99 & 11 & $10.7 \%$ & 1.64 \\
\hline Bladder & 103 & 3.48 & 15 & $14.6 \%$ & 1.80 \\
\hline Grooming & 104 & 3.37 & 11 & $10.6 \%$ & 1.55 \\
\hline Toilet use & 105 & 3.08 & 33 & $31.4 \%$ & 1.79 \\
\hline Feeding & 104 & 3.86 & 5 & $4.8 \%$ & 1.60 \\
\hline Transfer (e.g. bed to chair) & 105 & 2.94 & 40 & $38.1 \%$ & 1.90 \\
\hline Indoor mobility & 104 & 2.87 & 37 & $35.6 \%$ & 2.38 \\
\hline Dressing & 106 & 2.99 & 8 & $7.5 \%$ & 1.00 \\
\hline Stairs & 105 & 2.19 & 2 & $1.9 \%$ & 1.00 \\
\hline Bathing & 106 & 2.52 & 44 & $41.5 \%$ & 1.59 \\
\hline \multicolumn{6}{|c|}{ Domestic functioning assessment (maximum score $=4$ ) } \\
\hline Telephone & 103 & 3.17 & 1 & $1.0 \%$ & 3.00 \\
\hline Shopping & 102 & 1.75 & 28 & $27.5 \%$ & 1.21 \\
\hline Food preparation & 101 & 1.86 & 9 & $8.9 \%$ & 1.56 \\
\hline Housekeeping & 101 & 1.73 & 12 & $11.9 \%$ & 1.42 \\
\hline Laundry & 101 & 1.60 & 11 & $10.9 \%$ & 1.55 \\
\hline Outdoor mobility & 102 & 1.88 & 23 & $22.5 \%$ & 1.48 \\
\hline Medications & 101 & 2.04 & 1 & $1.0 \%$ & 1.00 \\
\hline Finances & 101 & 2.03 & 3 & $3.0 \%$ & 1.00 \\
\hline
\end{tabular}

only expected for a few applicants. Four applicants had an expected increase in hours of care per week, which was due to more time being taken in handling equipment. Only one in four of all care and assistance arrangements were sustainable if the equipment was not provided, with one in three likely to breakdown in either the short-term (within 6 months) or the long-term (greater than 6 months).

\section{Impacts on carers and on clients}

Provision of equipment was expected to have greatest impact on the physical effort and safety of carers and least likely to affect the independence and emotional well-being of carers (Fig. 1). The range of responses to each of the five 'impacts on carer' items suggests that each is capable of discriminating between applicants to varying degrees. The regression analysis found that the assessment of the impact on carers could be reduced, with the following items being retained (in order, with variation shown in parentheses):

- Physical effort, quality of life $(92.0 \%)$

- Physical effort, independence, quality of life $(96.2 \%)$

- Physical effort, emotional well-being, independence, quality of life $(98.0 \%)$

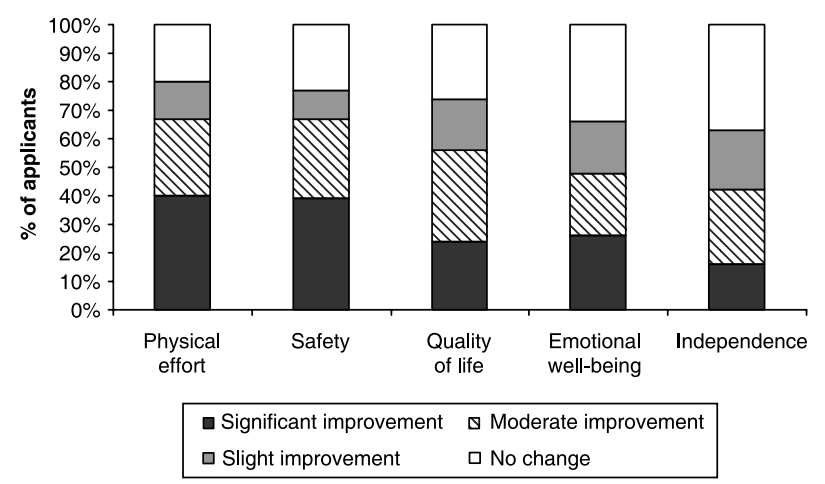

FIGURE 1: Impact of provision of requested item(s) on carers.

Provision of equipment was expected to have the greatest benefit for the applicant in the domains of safety and quality of life (Fig. 2).

\section{Expected benefits}

The assessment tool provides a measure of 10 potential benefits from providing equipment: improvement in client self care function; improvement in client domestic 


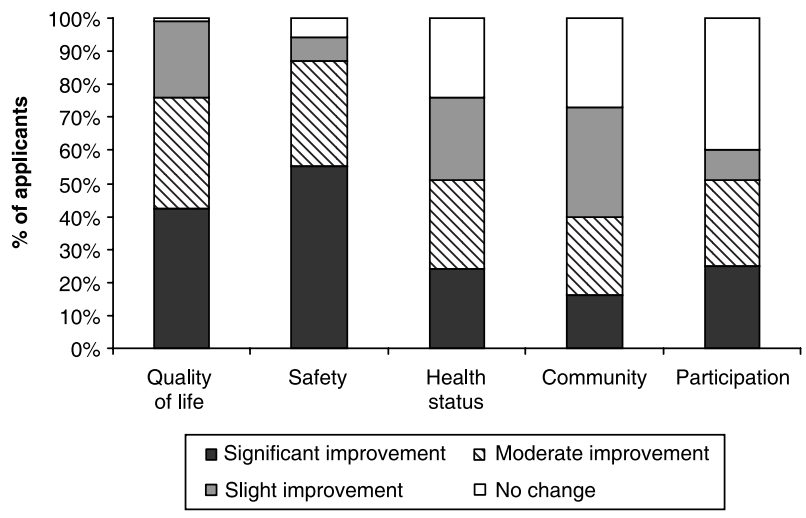

FIGURE 2: Impact of provision of requested item(s) on applicants.

function; reduction in the hours of care required by the client; enhanced sustainability of care arrangements; positive impact on the carer; and five positive impacts on the client (increased likelihood of remaining in the community/own residence, improved quality of life, increased community participation, improved safety and improved health status).

The regression analysis again found that the assessment of expected benefits could be reduced, with the results included in Table 5. The best model, in terms of the trade-off between number of items included and variation explained, would include six of the original 10 expected benefits, namely (i) improvement in self-care function; (ii) change in hours of care and assistance; (iii) sustainability of care/self-care arrangements; (iv) likelihood of remaining in community/own residence; (v) improvement in applicant's participation in social or community activities; and (vi) overall effect on applicant's health status.

This would account for $93.2 \%$ of the variation in expected benefits. This approach removes the domestic functioning assessment from the tool, so the measure of need would be based solely on assessment of self-care.

\section{Feedback from assessors}

Feedback sheets were completed for 37 adult assessments (response rate $34.9 \%$ ). Most were occupational therapists $(26,70.3 \%)$. Approximately half $(18,53 \%)$ said they found the assessments moderately or very difficult to make. Nevertheless, most $(23,68 \%)$ were very or moderately confident about the accuracy of their ratings. Twelve respondents $(32.4 \%)$ provided further comments. Seven related to the length of the assessment process, which was described as 'time-consuming', 'cumbersome' and 'not user friendly'. PADP assessors used the tools in parallel with their existing systems and the new assessment tool was perceived as an added burden.

Some respondents expressed concern that particular items or disabilities-lymphedema, safety, communication and feeding-were not addressed in the assessment. Several felt that the assessments failed to capture the complexity of the client's situation. One pointed out that many of the questions were addressed in an accompanying

TABLE 5: Analysis of expected benefits

\begin{tabular}{|c|c|c|c|c|c|}
\hline Domain & Items & $N$ & Mean & Correlation & $\begin{array}{l}\text { Variation explained by } \\
\text { individual domain or item }\end{array}$ \\
\hline Self-care & All 10 items & 93 & 2.3 & 0.599 & $35.9 \%$ \\
\hline Self-care - modified & $\begin{array}{l}\text { Bladder, toilet use, } \\
\text { indoor mobility }\end{array}$ & 93 & 2.1 & 0.573 & $32.8 \%$ \\
\hline Domestic & All 8 items & 93 & 1.6 & 0.588 & $34.6 \%$ \\
\hline Domestic - modified & $\begin{array}{l}\text { Shopping, housekeeping, } \\
\text { outdoor mobility }\end{array}$ & 93 & 1.7 & 0.610 & $37.2 \%$ \\
\hline Care and assistance & Hours of care & 93 & 1.7 & 0.405 & $16.4 \%$ \\
\hline provided to applicant & Sustainability & 93 & 2.4 & 0.588 & $34.6 \%$ \\
\hline Impact on carers & $\begin{array}{l}\text { Physical effort, emotional } \\
\text { well-being, independence, } \\
\text { quality of life and safety }\end{array}$ & 93 & 2.6 & 0.543 & $29.5 \%$ \\
\hline Impact on carers - modified & $\begin{array}{l}\text { Physical effort, independence, } \\
\text { quality of life }\end{array}$ & 93 & 2.6 & 0.521 & $27.1 \%$ \\
\hline \multirow[t]{5}{*}{ Impact on client } & Remain in community & 93 & 2.3 & 0.646 & $41.7 \%$ \\
\hline & Quality of life & 93 & 3.2 & 0.630 & $39.7 \%$ \\
\hline & Participation & 93 & 2.4 & 0.569 & $32.4 \%$ \\
\hline & Safety & 93 & 3.4 & 0.470 & $22.1 \%$ \\
\hline & Health status & 93 & 2.5 & 0.550 & $30.3 \%$ \\
\hline
\end{tabular}

Note: All correlations significant at the 0.01 level (two-tailed). 
narrative report from the occupational therapist, reflecting the fact that two systems were used in parallel during the field trial. For eight clients, respondents indicated that the assessment forms had missed some important information, including lymphedema and the distinction between outdoor mobility and the ability to use public transport.

Estimates of the time taken to complete the tool ranged from $40 \mathrm{~min}$ to over $1 \mathrm{~h}$. Therapists who completed only one or two assessments and were unfamiliar with the process took the longest. There was recognition that speed would increase with practice and that any further development of the tool would have to be integrated with existing systems.

\section{Feedback from PADP Committees}

Three of the four local PADP Committees gave feedback. Two were very comfortable with the idea of using need and capacity to benefit as the dimensions for assigning priority. There was some concern about whether the tool was sensitive enough to pick up changes in function for some clients, particularly those with low function. Nevertheless, the range of items assessed was considered appropriate and there were no additional areas they felt needed to be added to the assessment. One committee named several items of information routinely used in their existing system that were not captured by the assessment form, including carers' health and functional ability.

The third committee had some serious reservations. Assessment of both need and capacity to benefit was seen as subjective and not adequately capturing the issues faced by young people with a disability compared to aged people. It was felt that the tool might disadvantage elderly people applying for items for safety reasons.

Safety issues were considered of prime importance by all three committees. Items designed to address occupational health and safety problems for carers or prevent injury to applicants get priority. Members of two committees felt that safety issues should be given greater importance. In contrast, quality of life was seen as a less important issue.

All three committees wanted to include an applicant's 'story' in the assessment process, describing how the requested items fit with the applicant's diagnosis and his/her personal circumstances. The committees rely heavily on these descriptions, particularly in complex cases, and there was some concern that the assessment used in the study 'is reducing clients to a number' and 'does not give the information we need'. Without the accompanying narrative report, the assessment process was seen as narrow and incomplete.

The priority rating systems currently in use at these three sites differ in their details but all are essentially based on a waiting list system. Few applications (if any) are rejected outright, but applications tend to be divided into those that must be funded immediately and others, who go onto a waiting list. The length of the wait is not defined in terms of months, but different levels of urgency are implied.

\section{Discussion}

The consultation process, comments by stakeholders and feedback from field testing all supported the use of the concepts of need and capacity to benefit to assess applications for equipment, with the exception of one field test site. That site had reservations about what they saw as the subjective nature of this assessment process and concerns about the particular needs of young people with disabilities and the elderly.

The results indicate that the assessment tool could be reduced to a more manageable size as part of a 'tradeoff' between explaining variation and the practicalities of data collection. One caveat concerns the inclusion of items for safety, for both applicant and carer. The technical results suggest excluding items capturing 'safety' because they do not discriminate well between applicants (most applicants had high expected benefits for safety), but it was an issue frequently mentioned during pilot testing and the field trial. It was strongly supported by those who approve applications. Although it is technically not necessary to support allocation decisions, any assessment tool that did not incorporate safety would lack credibility with those involved in the current system.

There is a strong attachment to current systems that rely heavily on narrative reports. The message from field testing was that formal assessment cannot wholly replace these narrative reports. Some details of the applicant's story are seen as essential for justifying the need for equipment, and should be retained in some form.

Existing systems for PADP applications are effectively systems for managing demand by placing applicants in priority order on a waiting list. Consideration should be given to formally acknowledging this issue by including an assessment of how long the applicant might reasonably be expected to wait to receive the requested equipment.

Our results suggest that a standardised system for assessing requests for equipment from people with disabilities is possible. The two core dimensions of the assessment tool (need and capacity to benefit) provide a suitable basis for determining priority within a $2 \times 2$ matrix, ranging from lowest priority (low need/high function and low capacity to benefit) to highest priority (high need/low function and high capacity to benefit). Further work with a larger dataset is necessary to identify a suitable number of priority levels and the thresholds for each level of priority. An example of how this approach can be applied to PADP has been reported elsewhere (Stevermuer, Owen, Williams \& Masso, 2007). 


\section{Acknowledgments}

Jan Sansoni provided technical assistance with the literature and undertook the modification of the scoring of the Barthel index. Roy Harvey participated in the early stages of the study and tool design and reviewed feedback from the initial consultation process. Rob Gordon provided technical advice throughout the study. Louise Ramsay assisted with tool design, training of the assessors and consultation with the allocation committees. The study was funded by the New South Wales Health Department and was approved by the University of Wollongong/ Illawarra Area Health Service Human Research Ethics Committee.

\section{References}

Bradshaw, J. (1972). The concept of social need. New Society, March, 640-643.

Collin, C., Wade, D. T., Davies, S. \& Horne, V. (1988). The Barthel ADL index: A reliability study. International Disability Studies, 10, 61-63.

Cookson, R. \& Dolan, P. (2000). Principles of justice in health care rationing. Journal of Medical Ethics, 26, 323-329.

Eagar, K., Owen, A., Marosszeky, N. \& Poulos, R. (2006). Towards a measure of function for Home and Community Care Services in Australia: Part 1 - Development of a national standard approach. Australian Journal of Primary Health, 12, 73-81.

Eagar, K., Sansoni, J., Harvey, R. \& Owen, A. (2003). A $P A D P$ assessment tool to assist in determining priority of funding and the allocation of equipment, aids and appliances based on clinical need: Consultation paper. Wollongong, NSW: Centre for Health Service Development, University of Wollongong.

Eagar, K. \& Woods, K. (1999). Client assessment - the starting point for coordinating care. In Leigh, J. (ed) The Australian coordinated care trials: Methodological issues in trial design and evaluation. Phillip: ACT: Commonwealth Department of Health and Aged Care.

Green, J., Eagar, K. \& Owen, A. (2006). Towards a measure of function for Home and Community Care Services in Australia: Part 2 - Evaluation of the screening tool and assessment instruments. Australian Journal of Primary Health, 12, 82-91.

Hadorn, D. (1991). Setting health care priorities in Oregon: Cost-effectiveness meets the rule of rescue. Journal of the American Medical Association, 265, 2218-2225.

Hauck, K., Smith, P. C. \& Goddard, M. (2002). Priority setting for health; a literature review. Report prepared for the World Bank by the Centre for Health Economics, University of York.

Lawton, M. P. \& Brody, E. M. (1969). Assessment of older people: Self-maintaining and instrumental activities of daily living. Gerontologist, 9, 179-186.

Owen, A., Poulos, R. \& Eagar, K. (2001). Using the evidence to develop best practice models for identifying initial primary and Community care needs. Wollongong, NSW: Centre for Health Service Development, University of Wollongong.

Steultjens, E. M., Dekker, J., Bouter, L. M., Jellema, S., Bakker, E. B. \& van den Ende, C. H. (2004). Occupational therapy for community dwelling elderly people: A systematic review. Age and Ageing, 33, 453-460.

Stevermuer, T. L., Owen, A. \& Eagar, K. (2003). A priority rating system for the NSW home care service: Data driven solutions. Wollongong, NSW: Centre for Health Service Development, University of Wollongong.

Stevermuer, T. L., Owen, A., Williams, K. \& Masso, M. (2007). Priority rating for community care. Australian Health Review, 31, 592-602.

Weissert, W., Chernew, M. \& Hirth, R. (2003). Titrating versus targeting home care services to frail elderly clients: An application of agency theory and cost-benefit analysis to home care policy. Journal of Aging and Health, 15, 99-123. 